\title{
Synergistic Anti-cancer Activity of MH-30 in a Murine Melanoma Model Treated With Cisplatin and its Alleviated Effects Against Cisplatin-induced Toxicity in Mice
}

\author{
HAE-RAN PARK ${ }^{1}$, SUNG-KEE JO ${ }^{1}$, HYANG-HEE CHO ${ }^{1}$ and UHEE JUNG ${ }^{2}$ \\ ${ }^{1}$ Radiation Research Division, ${ }^{2}$ Environmental Safety Evaluation Research Division, \\ Korea Atomic Energy Research Institute (KAERI), Jeongeup, Republic of Korea
}

\begin{abstract}
Background/Aim: Although cisplatin is an effective anticancer drug, its toxic effects on normal tissues limit its use. We developed a herbal formula, MH-30, with increased fat-soluble polyphenols by improving the manufacturing method of HemoHIM. In this study, we examined whether the combination of $\mathrm{MH}-30$ with cisplatin exerts synergistic antitumor effect while it reduces cisplatininduced toxicities. Materials and Methods: MH-30 was produced by adding the ethanol-insoluble fraction to its extract after decocting herbs in $30 \%$ ethanol and water. We used a melanoma-bearing mice model to investigate synergistic anticancer effects. The NK cell activity and cytokine levels were measured by $\mathrm{Cr}^{51}$-release assay and ELISA. The AST, ALT, BUN, and creatinine levels were estimated in the serum. Results: $M H-30$ effectively inhibited melanoma growth in vitro. Furthermore, MH-30 had a synergistic effect in combination with cisplatin on melanoma growth inhibition in vitro and in vivo. In melanoma-bearing mice, cisplatin alone decreased the activity of $N K$ cells and the levels of IL-2 and IFN- $\gamma$, which were effectively restored by the combination of MH-30 with cisplatin. Combined treatment with MH-30 and cisplatin significantly inhibited the cisplatin-induced increase in the levels of AST, ALT, $B U N$, and creatinine. Conclusion: Combination of $\mathrm{MH}-30$ with cisplatin may be a beneficial anticancer treatment with reduced adverse effects.
\end{abstract}

This article is freely accessible online.

Correspondence to: Uhee Jung, Ph.D., Environmental Safety Evaluation Research Division, Korea Atomic Energy Research Institute (KAERI), 111,Daedeok-Daero 989 Beon-Gil, Yuseong-Gu, Daejeon 34057, Republic of Korea. Tel:+82 428688038, Fax: +82 428619560, e-mail: uhjung@kaeri.re.kr

Key Words: Chemotherapy, melanoma, herbal, cisplatin, anticancer, cisplatin-induced toxicity.
Melanoma is a malignant tumor of melanocytes, and its incidence has been increasing yearly in many countries (1). Furthermore, anticancer therapy for melanoma is complicated due to its resistance to chemical anticancer agents $(2,3)$. Chemotherapy is commonly used to directly kill cancer cells, however, in many cases, chemotherapy alone does not provide a satisfactory therapeutic outcome. In other words, therapeutically effective doses that may eliminate the tumors will lead to serious side effects. For this reason, a combination of chemotherapy with agents having different mechanisms of action has been studied and clinically tested (4-12).

Cisplatin (cis-diaminedichloroplatinum II) has been widely utilized for the therapy of several solid cancers. Although cisplatin has an excellent anticancer activity, its undesirable side effects, such as bone marrow toxicity, ototoxicity, nephrotoxicity, and hepatotoxicity limit its clinical usage (13-16). Efforts to reduce these side effects often have been focused on reducing the dose, frequency and duration of cisplatin treatment. The exact cellular and molecular mechanisms of cisplatin-induced toxicity are not clear, but the oxidative stress caused by cisplatin has been suggested as a key factor (17-19). When cisplatin is administered to the human body, it accumulates primarily in the liver and kidneys, where it leads to increased generation of reactive oxygen species (ROS) and disruption of the cellular oxidative defense system $(18,20,21)$. Therefore, treatment with antioxidants (as chemo-protectors) has been evaluated to ameliorate the severity of cisplatin-induced toxicity in various animals (22-29), however, they have not been proven clinically effective in cancer patients, which necessitates further research.

In many studies, natural products and traditional herbal medicines are considered key players in pharmacology and especially in cancer research as complementary and alternative medicines (CAM; defined by the National Center as a group of diverse medical and health care systems) (3033). Traditional herbal medicines are characterized as herbal cocktails with multiple phytochemicals in a single formula. 


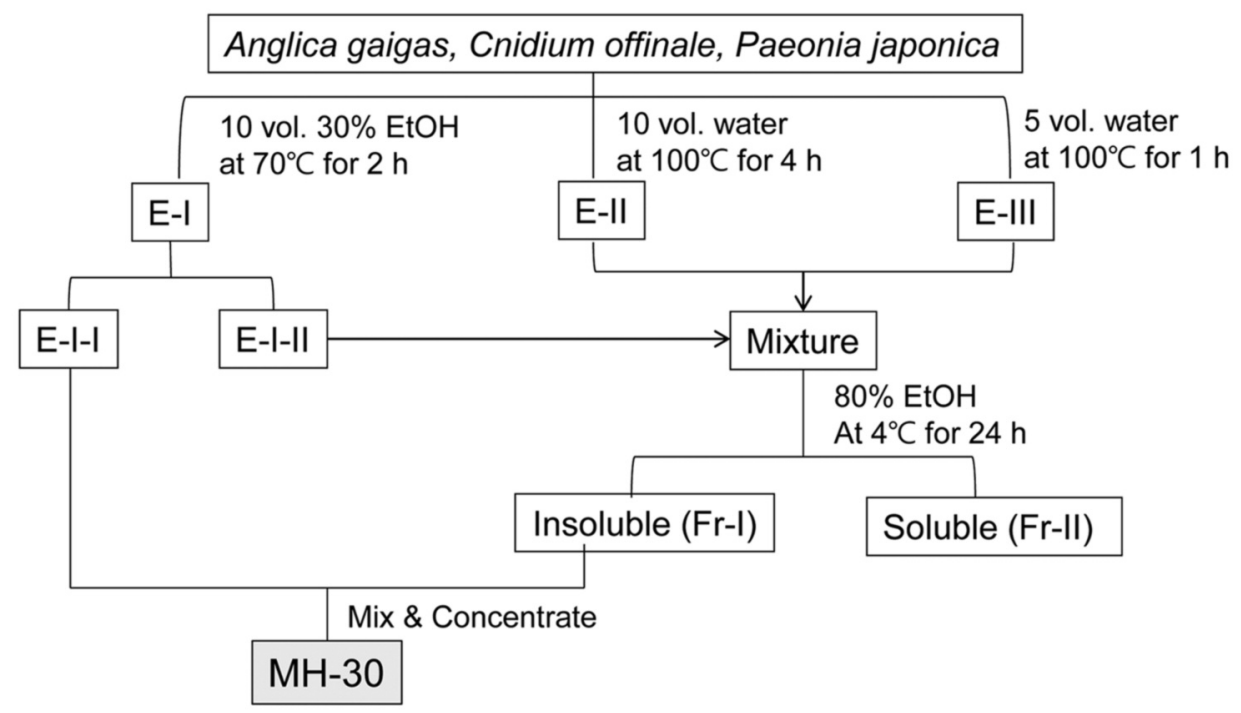

Figure 1. The scheme for producing the herbal formula $\mathrm{MH}-30$.

Consequently, these traditional herbal formulas have the advantage of maximizing the therapeutic effects by synergistically affecting multiple biological and pathological processes.

We have previously formulated a novel herbal mixture termed HemoHIM, which was produced by adding its polysaccharide fraction after extracting the herbal mixture consisting of Angelica Radix, Cnidium Rhizoma and Paeonia Radix by hot water. We produced this herbal cocktail to protect stem cells of the intestine and bone marrow and to promote immune system recovery against oxidative stresses, such as that produced by irradiation $(34,35)$. In our previous studies, various activities of HemoHIM have been reported in several in vitro and in vivo models (36-44). In addition, HemoHIM enhances the treatment efficacy of cisplatin or ionizing radiation in melanoma-bearing mice $(45,46)$. HemoHIM decocted by hot water has low levels of fatsoluble polyphenols, although there are reports that the fatsoluble polyphenols exert higher antioxidant activity than the water-soluble polyphenols $(47,48)$. Accordingly, we decocted the above three herbs by $30 \%$ ethanol and hot water to improve the antioxidant efficacy by increasing the levels of fat-soluble polyphenols and designated the product $\mathrm{MH}$ 30. Recently, we showed through HPLC analysis that MH30 has a higher content of fat-soluble polyphenol compounds than HemoHIM (8.7 times higher for decursin), suggesting that MH-30 has significantly increased protective efficacy against ionizing radiation compared with HemoHIM (49).

In the current study, we determined the synergistic effect of the combination of MH-30 with cisplatin on the anti-tumor activity without interfering with cisplatin both in vitro and in vivo. Furthermore, we examined whether nephrotoxicity and hepatotoxicity induced by cisplatin were mitigated by $\mathrm{MH}$ 30 administration.

\section{Materials and Methods}

Animals. Female 8-week-old C57BL/6N (H-2 $\left.{ }^{\mathrm{b}}\right)$ mice and Charles River CD-1 (ICR) mice were purchased from Orient Inc. (Charles River Technology; Seoul, Republic of Korea). The animals were housed in specific pathogen-free conditions at a controlled environment, $22 \pm 2^{\circ} \mathrm{C}$ and $50 \pm 5 \%$ relative humidity. Mice were fed standard animal diet and water ad libitum. The mice used in all experiments were sacrificed by asphyxiation with $\mathrm{CO}_{2}$ gas. The animal experiments were conducted in strict accordance with the guidelines for the use and care of laboratory animals of Ministry of Health and Welfare, Republic of Korea. All protocols were approved by the Institutional Animal Care and Use Committee of the Korea Atomic Energy Research Institute (KAERI-IACUC) and included criteria for euthanasia to minimize suffering.

Preparation of $\mathrm{MH}-30$. The herbal medicines were purchased from the Gyeongdon Herbal Medicine Market in Seoul, Republic of Korea. Varieties were identified by traditional classification from the Gyeongdong Herbal Medicine Market and theses herbs are designated as edible raw ingredients by the Korean Food Code. A mixture of three edible medicinal herbs, Angelica Radix (root of Angelica gigas Nakai), Cnidii Rhizoma (rhizome of Cnidium officinale Makino), and Paeonia Radix (root of Paeonia japonica Miyabe), was decocted for $2 \mathrm{~h}$ at $70^{\circ} \mathrm{C}$ in $30 \%$ ethanol to obtain an ethanol extract (E-I). To obtain a water extract, sediments after extracting with ethanol were decocted in boiling water two times (E-II and E-III). Then, a part of E-I was blended with E-II and E-III, and the mixture was fractionated into an ethanol-soluble fraction (Fr-II) and an ethanol-insoluble polysaccharide fraction (Fr-I) by precipitation in $80 \%$ ethanol. $\mathrm{MH}-$ 30 was prepared by adding the ethanol-insoluble polysaccharide fraction to the other part of E-I (Figure 1). The percentages of crud polysaccharide in the final $\mathrm{MH}-30$ were $35 \sim 45 \%$. 

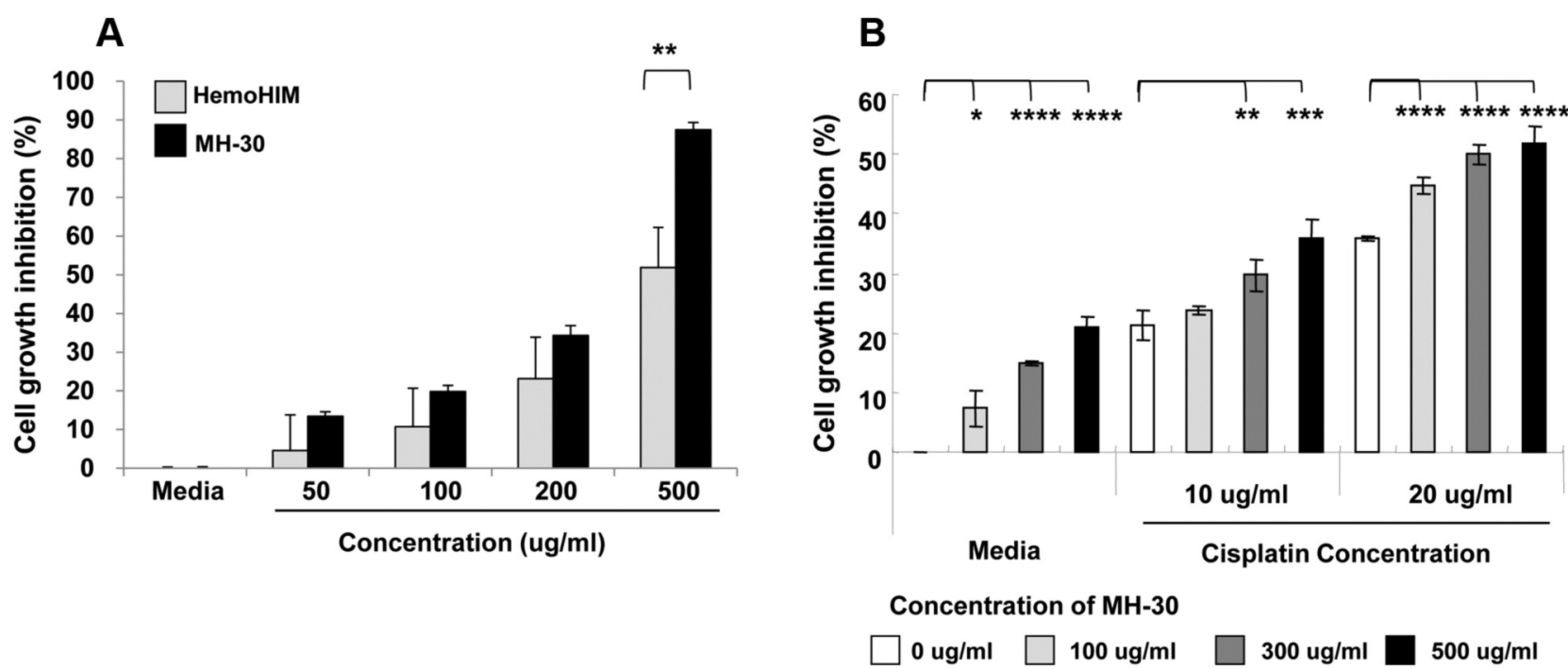

Figure 2. MH-30 inhibits melanoma cell growth and enhanced the effect of cisplatin in vitro. The melanoma cells were seeded at a density of $7 \times 10^{3}$ cells per well. (A) At 24 h after melanoma seeding, cells were treated with various concentration of MH-30 or HemoHIM for 48 h. (B) At 24 h after melanoma seeding, cells were treated with various concentrations of $\mathrm{MH}-30$ and with or without various concentrations of cisplatin for 24 h. After incubation, the CCK-8 solution was added to each well and then the optical density was measured. Data are presented as the Mean $\pm S D . * p<0.05$, $* * p<0.01, * * * p<0.005$ and $* * * * p<0.001$.

Cells. B16F10 (Melanoma cell line; CRL-6475) and YAC-1 cell lines (Molony virus induced leukemia; TIB-160) were purchased from ATCC (Rockville, MD, USA) and cultured as we have previously reported $(45,46)$.

Melanoma cell growth assay in vitro. The effect of cisplatin and MH-30 on the number of viable melanoma cells was assessed by CCK-8 (WST-8; Dojindo Lab, Kumamoto, Japan) as per the manufacturer's instructions. The detailed method has been previously reported (45).

Melanoma-injected mice model. Mice were divided randomly into three groups of eighteen twenty-two mice: Control, Cisplatin and Cisplatin+MH-30. On day $1,2 \times 10^{5}$ B16F10 melanoma cells were inoculated subcutaneously into left femoral region of mice. Three days after cancer cell implantation, a final concentration of 100 $\mathrm{mg} / \mathrm{kg}$ body weight (B.W.) of MH-30 intubated every day until the end of the experiment, while the control group received only water. Cisplatin was injected intraperitoneally at $3 \mathrm{mg} / \mathrm{kg} \mathrm{B.W}$. on days 7 , $8,13,14,19$ and 20 (total six injections). The experimental method of the administration of cisplatin and $\mathrm{MH}-30$ after melanoma injection is summarized in Figure 3. Mice were monitored every other day for tumor growth and weighted two times weekly.

Preparation of spleen lymphocytes. On day 19 after B16F10 melanoma inoculation, the spleen lymphocytes were obtained from the spleens. The isolation method of the spleen lymphocytes has been previously reported (45).

$\mathrm{Cr}^{51}$-release assay. NK cell activity was measured by ${ }^{51} \mathrm{Cr}$-release assay as described previously $(45,46)$. Briefly, spleen effector cells were cocultured with ${ }^{51} \mathrm{Cr}$-sodium chromate-labeled YAC-1 target. After incubation for 4 hours, ${ }^{51} \mathrm{Cr}$ released in the culture supernatant was detected by gamma counter. The lysis was calculated using the following equation: \% lysis $=\{[\mathrm{CPM} \quad$ (experimental) $-\mathrm{CPM}$ (spontaneous)]/[CPM (maximum)-CPM (spontaneous)] $\} \times 100$.

Measurement of cytokines in the cell culture supernatant. To detect IL-2 and IFN-gamma in the culture supernatant, the spleen lymphocytes $\left(2 \times 10^{6}\right.$ cells/24-well $)$ were cultured with $1 \mathrm{mg} / \mathrm{ml}$ Concanavalin (Con) A for 1 or 2 days. The cytokine levels were determined using an ELISA according to the manufacturer's instructions (http://www.bdbiosciences.com). All OptEIA ${ }^{\mathrm{TM}}$ sets were purchased from BD PharMingen (SanDiego, CA, USA).

In vivo experimental design to assay cisplatin-induced toxicity. CD1 (ICR) mice were divided randomly into four groups of twelve mice: Control, MH-30 only, Cisplatin and Cisplatin+MH-30. MH30 was intubated at $100 \mathrm{mg} / \mathrm{kg} \mathrm{B.W}$. every day for 20 days, while the control group was administrated only water. From day 3 after the initial oral feeding of $\mathrm{MH}-30$, cisplatin was injected intraperitoneally as described above (Figure 3).

Histopathological examination of kidney and liver tissue. On day 17 after the initial injection of cisplatin, the kidney and the liver were harvested and paraffin embedded following fixation in $10 \%$ buffered formalin for 2 days. The five-micron paraffin-embedded sections were cut and stained with hematoxylin and eosin (H\&E) for histopathological examination and observed under the light microscope at $\times 200$ magnifications.

Measurement of biochemical parameters. Whole blood of mice was collected from the retro-orbital veins using heparinized capillary tubes. After centrifugation, sera were collected, and the levels of serum BUN, creatinine, AST, and ALT were analyzed using the AU680 Chemistry System (Beckman Coulter, Brea, CA, USA). 


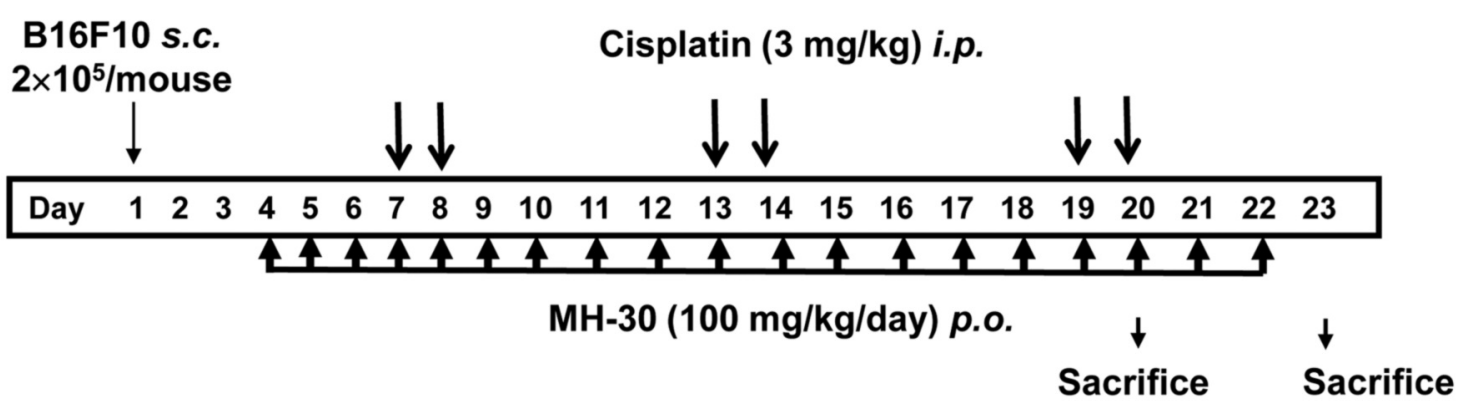

Figure 3. The experimental schedule used for assessing the synergistic anticancer efficacy of $M H-30$ and cisplatin in melanoma-bearing mice. B16F10 melanoma cells $\left(2 \times 10^{5} /\right.$ mouse $)$ were inoculated subcutaneously into the left femoral region of mice. MH-30 was given daily at $100 \mathrm{mg} / \mathrm{kg}$ B.W. until the end of the experiment. Cisplatin was intraperitoneally injected at $3 \mathrm{mg} / \mathrm{kg} \mathrm{B.W.} \mathrm{on} \mathrm{days} \mathrm{7,} \mathrm{8,} \mathrm{13,} \mathrm{14,} 19$ and 20 (total six injections).

Statistical analysis. The differences between the groups are presented as mean \pm S.D. The significance of differences was analyzed by the Student's $t$-test using SPSS Statistic 22 (IBM, New York, USA). Probability values of less than 0.05 were statistically significant.

\section{Results}

MH-30 enhances the effect of cisplatin on B16F10 cells in vitro. Firstly, we examined the effect of MH-30 on the growth of B16F10 melanoma cells and compared it with that of HemoHIM. In our previous study, HemoHIM $(100 \mu \mathrm{g} / \mathrm{ml})$ did not inhibit melanoma growth in vitro (45). As shown in Figure 2A, treatment with $\mathrm{MH}-30$ resulted in a concentration-dependent reduction in the viability of B16F10 melanoma cells. MH-30 showed a significantly higher inhibitory effect on melanoma growth than HemoHIM. Therefore, we considered that the high content of fat-soluble polyphenols in MH-30, compared with HemoHIM, contributed greatly to the inhibition melanoma growth.

In order to examine the synergistic effect of $\mathrm{MH}-30$ and cisplatin on melanoma growth, B16F10 melanoma cells were cultured with MH-30 and cisplatin for $24 \mathrm{~h}$. The dose of cisplatin was chosen to be $10 \mu \mathrm{g} / \mathrm{ml}$ or $20 \mu \mathrm{g} / \mathrm{ml}$ less than the $\mathrm{IC}_{50}$ values to observe inhibitory effects of more than $50 \%$ when treated with $\mathrm{MH}-30$ and cisplatin. Figure 2B shows the concentration-dependent inhibitory effect of both MH-30 and cisplatin on B16F10 cells treated with one or both drugs. The inhibition of melanoma growth was significant at all concentrations of cisplatin in the presence of $300 \mu \mathrm{g} / \mathrm{ml}$ or $500 \mu \mathrm{g} / \mathrm{ml} \mathrm{MH}-30$. The combination of 100 $\mu \mathrm{g} / \mathrm{ml} \mathrm{MH}-30$ with cisplatin gave significant results only at $20 \mu \mathrm{g} / \mathrm{ml}$ cisplatin. These results suggest that the cytotoxic activity of MH-30 alone or in combination with cisplatin can be partly explained by a direct effect on melanoma, and $\mathrm{MH}-$ 30 does not interfere with cisplatin in vitro.

Synergistic anticancer effect of $\mathrm{MH}-30$ and cisplatin in B16F10 melanoma-transplanted mice. In the following experiments, the antitumoral effect of $\mathrm{MH}-30$ in combination with cisplatin was explored in melanoma-bearing mice is summarized in Figure 3. As shown in Figure 4A, the mean tumor weight of mice receiving $\mathrm{MH}-30$ (100mg/kg B.W.) together with cisplatin ( $3 \mathrm{mg} / \mathrm{kg}$ B.W.) was significantly decreased when compared with that of those receiving either treatment alone $(p<0.005$ compared with cisplatin only group). The tumor weight in the cisplatin only group was decreased significantly to $47.16 \%$ compared to the control mice and to $65.75 \%$ by the combined treatment with MH-30 and cisplatin. Despite growth inhibition of melanoma in vitro (Figure 2), when MH-30 (100 mg/kg BW) was administrated alone without cisplatin, there was no reduction in tumor weight compared to the control group (Data not shown). This result may indicate that the administrated dose of $\mathrm{MH}-30$ was not that required to kill tumor cells directly (Figure 2A). Photographs are shown in Figure 4B.

The enhanced anti-cancer efficacy of $\mathrm{MH}-30$ in combination with cisplatin involved $N K$ cell activity and IFN-gamma secretion. MH-30 itself did not directly inhibit tumor growth in melanoma-transplanted mice, instead had a synergistic effect with cisplatin. We, therefore, hypothesized that $\mathrm{MH}$ 30 has different mechanisms for anti-cancer efficacy in melanoma-implanted mice. Since it has been reported that it supports the activity of diverse immune cells including NK cells, macrophages, and cytotoxic $\mathrm{T}$ cells for cancer surveillance, we next investigated the effect of $\mathrm{MH}-30$ on the cytotoxic activity of NK cell on day 19 after B16F10 injection in mice. Figure 5A shows that treatment of melanoma-implanted mice with cisplatin alone significantly decreased the activity of NK cells, which was restored by the combined treatment with MH-30 and cisplatin $(p<0.05)$. MH-30 alone had no significant effect on the cytotoxic activity of NK cells.

IL-2 and IFN-gamma are known to be potent activators for the cancer cell killing function of NK and Tc cells. To evaluate the secretion of IL-2 and IFN-gamma in melanoma- 


\section{(A) Tumor weight}

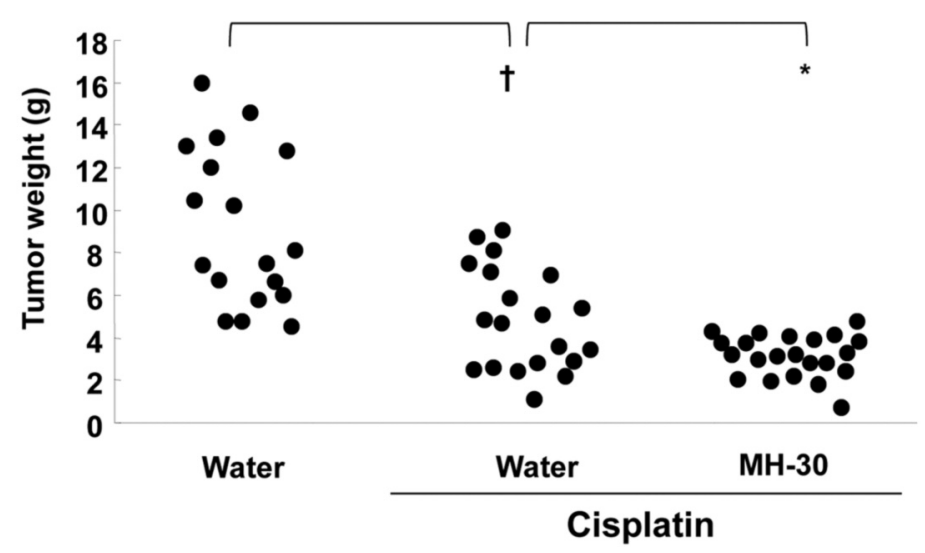

\section{(B) Tumor photograph}

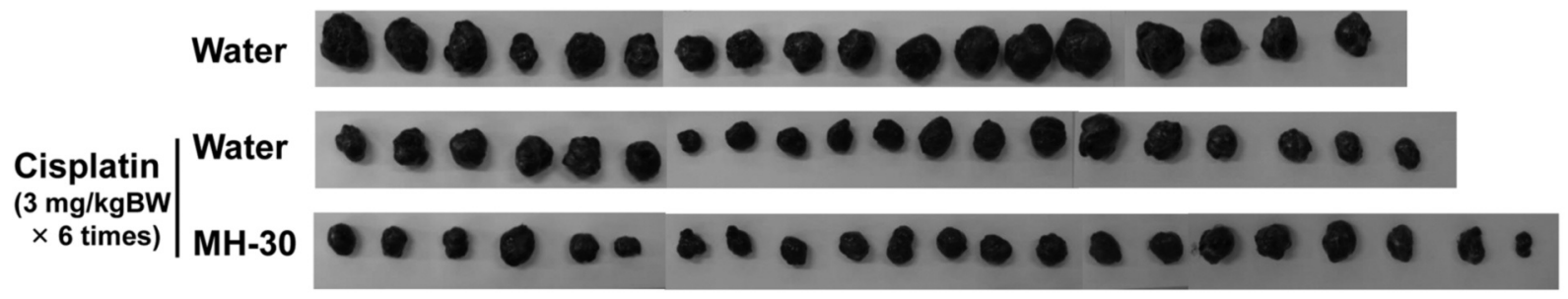

Figure 4. MH-30 has synergistic anticancer effects in combination of cisplatin in melanoma-bearing mice. All mice treated as described in figure 3 were sacrificed on day 22 after B16F10 melanoma inoculation. (A) The tumor weight of each group was measured. (B) Photographs of melanoma solid tumors taken from all mice of each group. There were eighteen twenty-two mice in each group. Data are presented as the Mean \pm SD. ${ }^{\dagger} p<0.001$ compared with control group; * $p<0.005$ compared with only cisplatin treated group.

implanted mice, spleen lymphocytes prepared on day 19 after melanoma injection were cultured with ConA for 24 or $48 \mathrm{~h}$. IL-2 levels were reduced in the cisplatin alone group, and restored by the combined treatment with $\mathrm{MH}-30$ (Figure 5B). However, the levels of IL-2 were not statistically significantly different. Figure $5 \mathrm{C}$ shows that cisplatin alone significantly decreased the levels of IFN-gamma $(p<0.01$ compared with control mice), which were significantly increased in the group receiving combined administration of MH-30 and cisplatin $(p=0.08)$.

Protective activity of $\mathrm{MH}-30$ on the cisplatin-induced hepatotoxicity and nephrotoxicity. It is known that cisplatin accumulates well in the liver and kidneys, causing undesirable side effects in these organs $(13,14,19)$. Cisplatin induces oxidative stress, which is one of the mechanisms of toxicity. Previous studies have revealed that MH-30 had higher superoxide anion and hydroxyl radical scavenging activity than HemoHIM that showed protective activity against cisplatin-induced nephrotoxicity (45). We, therefore, examined whether $\mathrm{MH}-30$ might reduce damages induced by cisplatin. It has been reported that a minimum dose of cisplatin inducing nephrotoxicity in rats is $5 \mathrm{mg} / \mathrm{kg}$ body weight $(29,30)$. Based on this report, in this study, cisplatin was given intraperitoneally at $3 \mathrm{mg} / \mathrm{kg} \mathrm{B}$.W. twice a week for three weeks (total six injections; Figure 6A).

Body weight loss was observed from day 9 after the first injection of cisplatin, and there was a significant difference between cisplatin and normal control from day 13 (Figure $6 \mathrm{~B})$. However, MH-30 significantly ameliorated body weight loss in cisplatin-treated mice. In addition, the liver and the kidney weight significantly decreased by $18.98 \%(p=0.002)$ and $17.87 \%(p=0.001)$ in the cisplatin only group, respectively. The group receiving the combined treatment of MH-30 and cisplatin showed no statistically significant decrease.

The hepatotoxicity of cisplatin was assessed by measuring the levels of AST and ALT in the serum, and by histopathological examination on day 3 after the final injection of cisplatin. MH-30 alone for 20 days did not affect the liver function, whereas the serum AST and ALT levels in the mice that received cisplatin only were significantly 


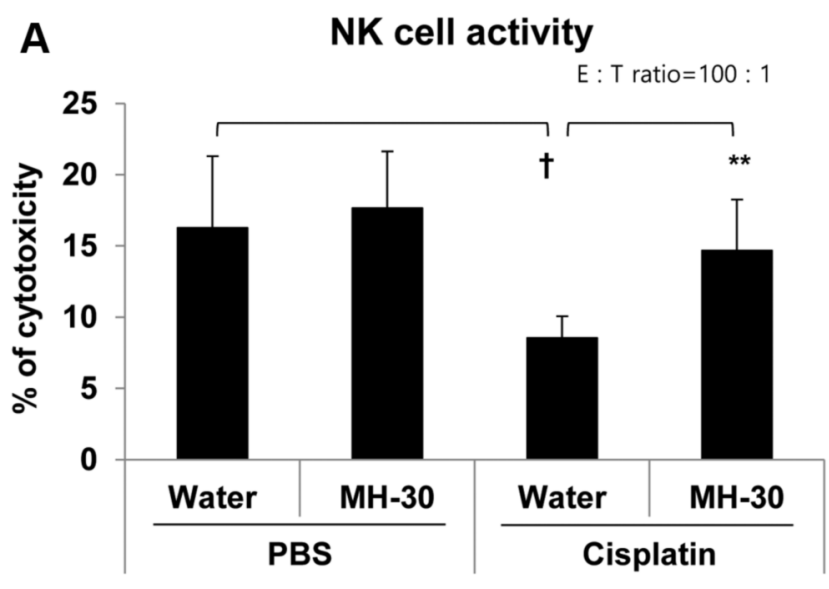

B

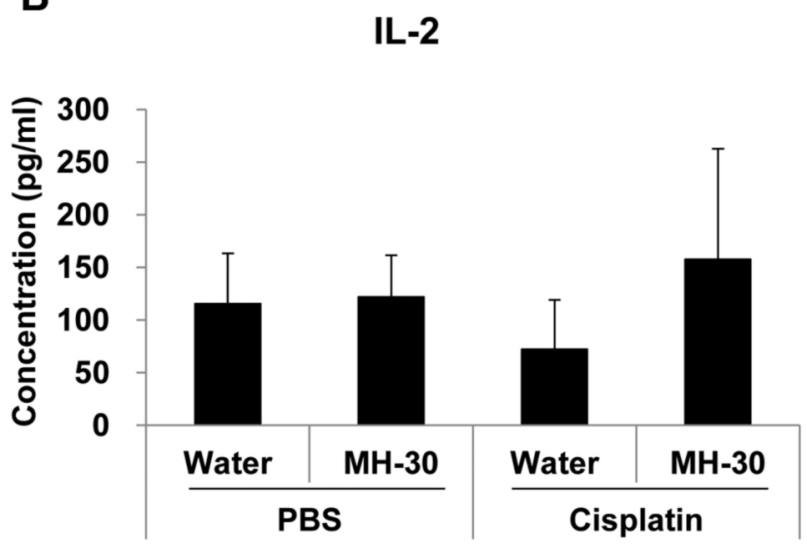

C

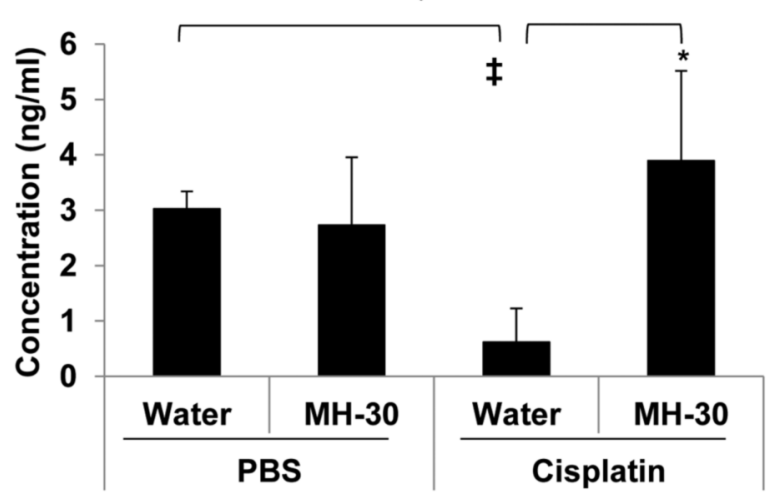

Figure 5. Effect of MH-30 on the cancer cell killing activity of NK cells and on the secretion levels of IL-2 and IFN-gamma in melanoma-bearing mice. On day 19 after B16F10 melanoma inoculation, spleen lymphocytes were isolated using a Ficoll-Hypaque density gradient centrifugation. (A) The cancer cell killing activity of NK cells was determined by ${ }^{51}$ Cr release assay as described in Materials and Methods. (B), (C) Spleen lymphocytes were cultured with ConA $(1 \mathrm{mg} / \mathrm{ml})$. After 1 or 2 days, IL-2 and IFN-gamma in the culture supernatants were measured by ELISA as described in Materials and Methods. There were six mice in each group. Data are presented as the Mean $\pm S D$. ${ }^{\dagger} p<0.05$ and ${ }^{\star} p<0.01$ compared with control group; *p<0.1 and **p<0.05 compared with only cisplatin treated group.

increased. Combined treatment with $\mathrm{MH}-30$ and cisplatin remarkably prevented the cisplatin-induced increase in AST and ALT levels in serum (Figure 7A). Despite the significant differences in the biochemical parameters, no histopathological damages were observed in the liver of the mice treated with $\mathrm{MH}-30$ alone, cisplatin alone, or the combination of cisplatin and MH-30 (Figure 7B).

The levels of BUN and creatinine in the serum were measured to assay for cisplatin-induced nephrotoxicity. The mice administered with MH-30 only for 20 days did not show any kidney dysfunction at the histopathological level (Figure 8B) as well as at the biochemical parameters level (Figure 8A). In contrast, cisplatin only injection resulted in a statistically significant increase in serum BUN and creatinine, indicating impaired renal function (Figure 8A). $\mathrm{MH}-30$ effectively blocked the cisplatin-induced increase in serum BUN and creatinine levels. In addition, in the histopathological examination of the kidney, cisplatin injection led to renal tubular cell necrosis, which was effectively reversed by the co-administration of $\mathrm{MH}-30$ (Figure 8B).

\section{Discussion}

Several studies have confirmed that natural herbal medicines may control a variety of human diseases, including tumor (32, 50-52). Traditional medicines are herbal cocktails containing multiple herbs in a single formula. These formulas are usually prepared by decocting extracts with boiling water, a traditional extraction method. In case of decocted extracts, some chemical interactions occur between the natural constituents that exist in the formula's ingredient 
A

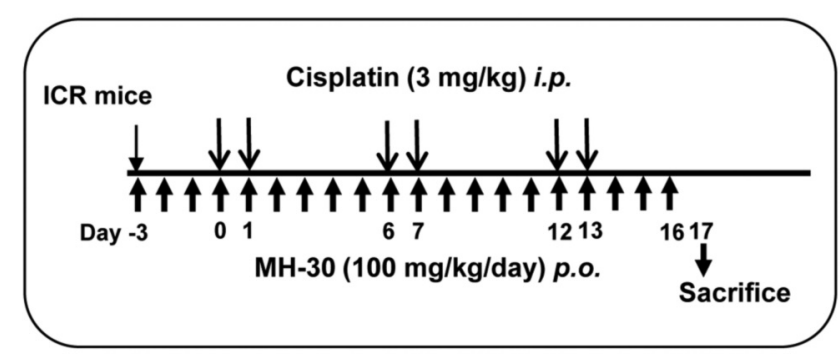

C

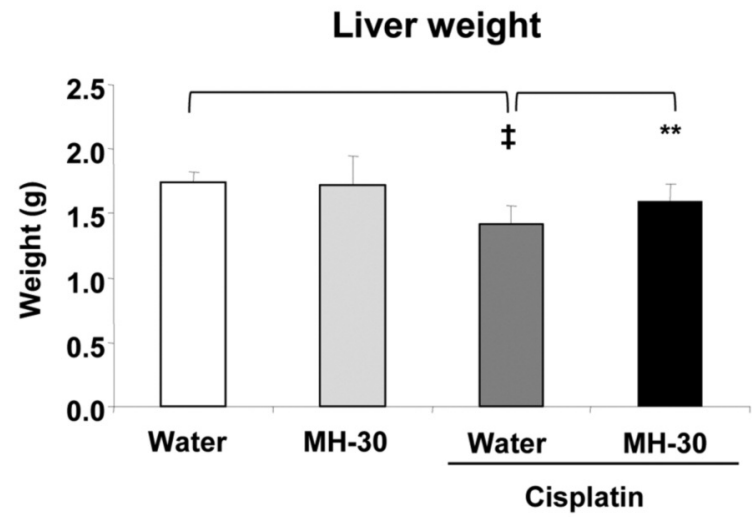

B

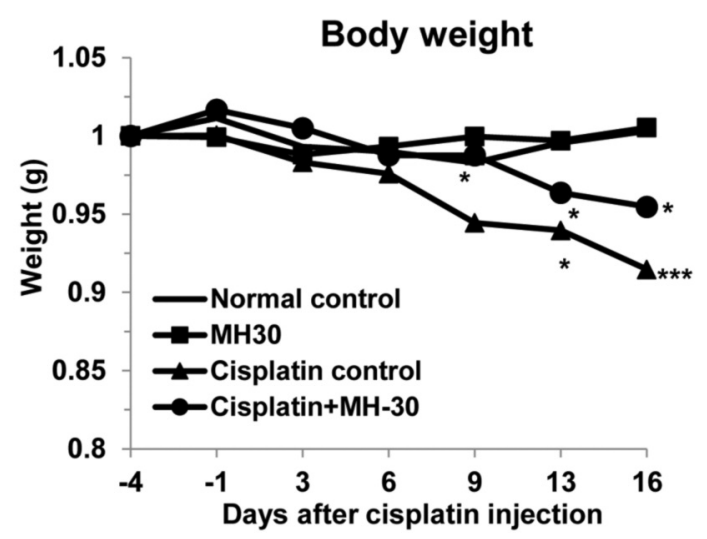

Kidney weight

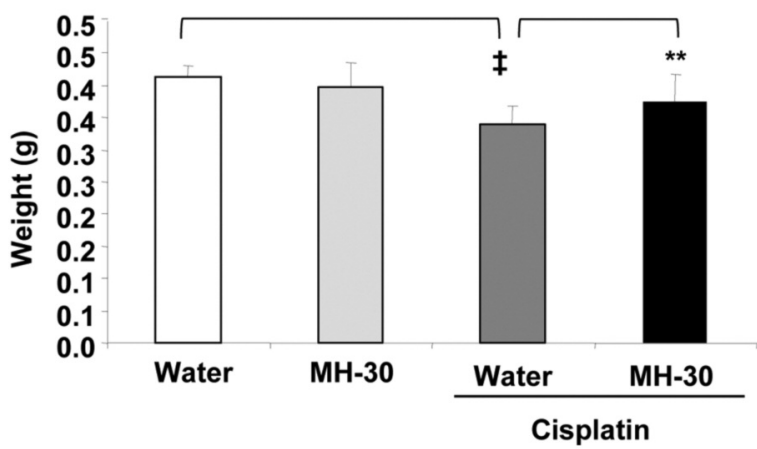

Figure 6. MH-30 administration prevents cisplatin-induced body, liver, and kidney weight loss. (A) The experimental schedule for assessing the cisplatin-induced damages in vivo. MH-30 was given daily at $100 \mathrm{mg} / \mathrm{kg} \mathrm{B.W.for} 20$ days. From day 3 after initial oral feeding of MH-30, cisplatin was intraperitoneally injected at $3 \mathrm{mg} / \mathrm{kg}$ B.W. twice a week for three weeks. (B) Body weight of all groups was measured once every three or four days. (C) On day 17 after initial injection of cisplatin, the liver and the kidneys of all groups were removed, and their weight was measured. There were twelve mice in each group. Data are presented as the Mean $\pm S D .{ }^{\dagger} p<0.1$ and ${ }^{\star} p<0.01$ compared with the control group; ${ }^{*} p<0.05$ and $* * p<0.01$ compared with the only cisplatin treated group.

herbs during decoction. Thus, decoction may change the rate of extraction of the active components and create new artificial substances, which can have new pharmacological activities. In traditional medicines, the herbal cocktail and new substances produced by decoction have the advantage of having the desired therapeutic effects while reducing side effects (33).

Previously, we have produced a novel medicinal herbal mixture known as HemoHIM, comprising three edible herbs (Angelica Radix, Cnidium Rhizoma and Paeonia Radix), and have reported various effects of HemoHIM in several models in vitro and in vivo (35-46). HemoHIM has low levels of fatsoluble polyphenols because it is decocted with boiling water in a traditional way. We recently developed $\mathrm{MH}-30$ from the same herbs was HemoHIM by decocting with $30 \%$ ethanol and hot water to enhance the fat-soluble polyphenol contents and confirmed that various fat-soluble polyphenol compounds in MH-30 were at higher levels compared to HemoHIM (49). Decursin contents in MH-30 were 8.7-fold higher than HemoHIM. In our previous study, HemoHIM did not directly inhibit tumor growth in vitro (45). Treatment with complementary and alternative medicines (including traditional medicine) is usually used as adjuvant instead of conventional treatment. However, MH-30 appeared to directly inhibit melanoma viability in a concentrationdependent manner in vitro. Our results support the conclusion that the fat-soluble polyphenols in $\mathrm{MH}-30$ contributed to inhibition melanoma growth. There are many reports that decursin exhibits anticancer activity by inhibiting the Wnt/ $\beta$ catenin pathway, inducing cell cycle arrest and apoptosis, and inhibiting VEGF-induced angiogenesis, and also by inhibiting metastasis by targeting MMP-9 activity (53-56). In addition, MH-30 showed a synergistic effect in combination with cisplatin on melanoma growth inhibition in vitro. 

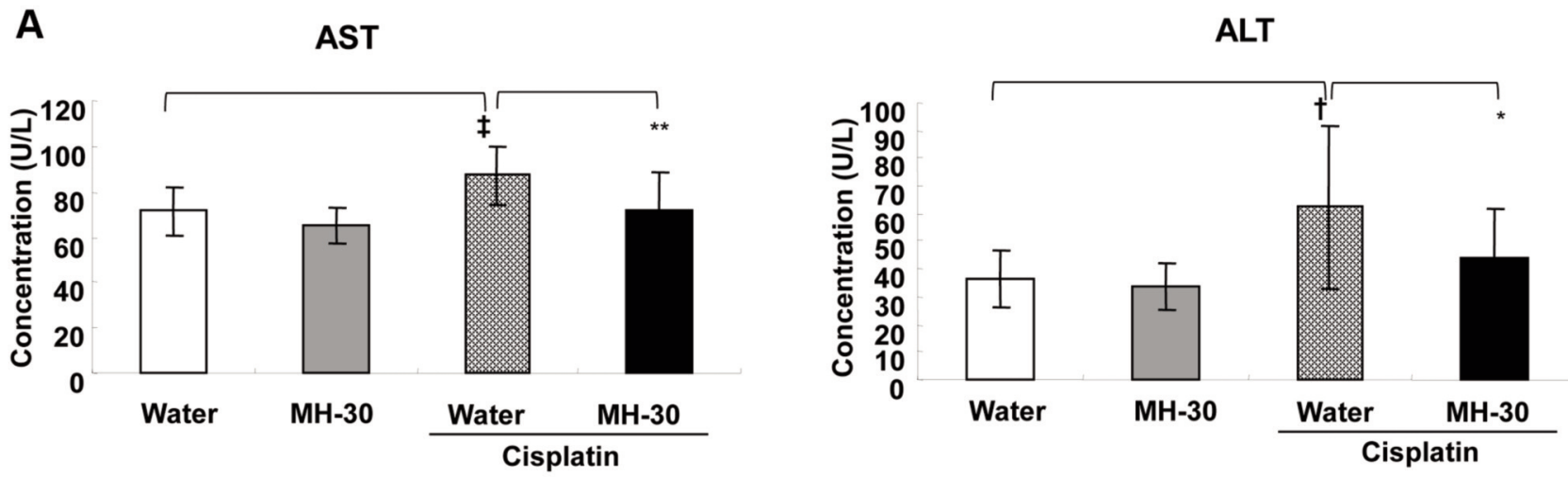

B
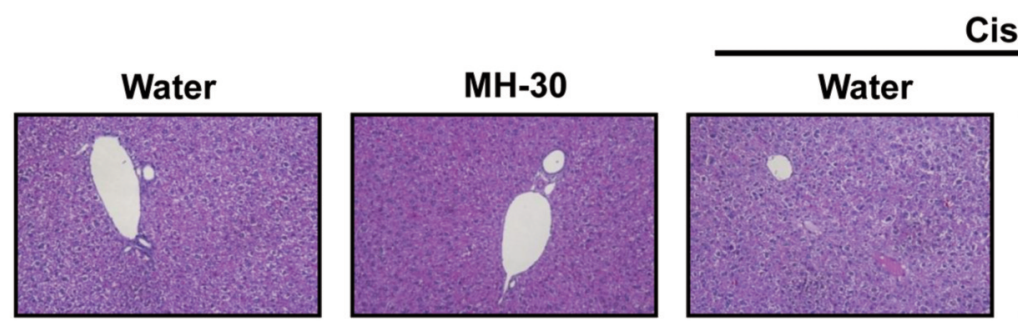

Cisplatin
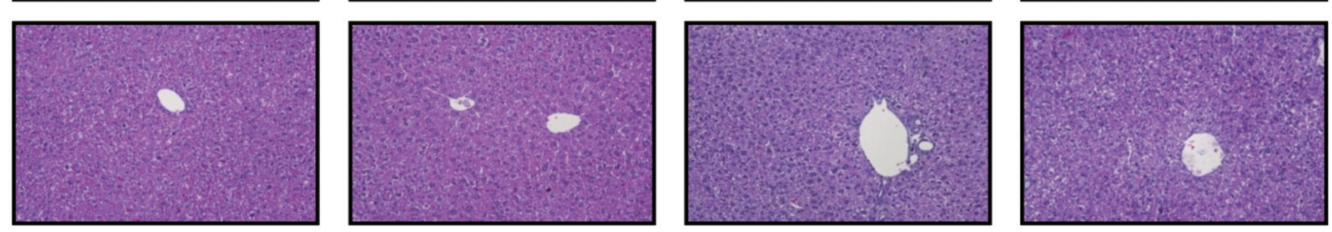

Figure 7. MH-30 administration reduces cisplatin-induce hepatotoxicity. On day 17 after initial injection of cisplatin, serum was prepared through clotting of whole blood collected from the retro-orbital veins and the liver was removed and fixed in 10\% buffered formalin for 2 days. (A) The levels of serum AST, and ALT were analyzed using the AU680 Chemistry System. (B) The paraffin-embedded sections (5 mm thick) were stained with hematoxylin and eosin $(H \& E)$ for histopathological examination and observed under light microscope at $\times 200$ magnification. The result shown is representative from each group. There were twelve mice in each group. Data are presented as the Mean $\pm S D$. ${ }^{\dagger} p<0.05$ and ${ }^{\ddagger} p<0.01$ compared with the control group; $* p<0.1$ and $* * p<0.05$ compared with the only cisplatin treated group.

The results of the present study indicated that the anticancer effect of $\mathrm{MH}-30$ is mediated through the restoration of the NK cell activity and the secretion of IL-2 and IFN-gamma. Many studies on enhancing the activity of NK cells against tumor cells have been conducted $(57,58)$. This is because NK cells can kill cancer cells that have diminished MHC I expression and evade recognition of Tc cells $(57,58)$. In addition, NK cells are involved in the enhancement of the activity of various immune cells, such as dendritic cells, Th cells and Tc cells (59). It is generally believed that IL-2 and IFN-gamma are effective stimulators of the activity of NK and Tc cell to lyse tumor targets. Especially, IFN-gamma can increase the expression of class I MHC on the surface of tumor cells to allow Tc cells to recognize and lyse them $(60,61)$. The combination of cytokines with chemotherapeutic drugs has been examined in depth as cancer therapy in both animal experimental and clinical studies (62). Nevertheless, the clinical usages of these cytokines have been examined very carefully due to their unwanted side effects and dose-limiting toxicities. Generally, herbal cocktails containing several herbs may offer the merit of the maximal therapeutic effects with minimal adverse effects (33). In our present study, we demonstrated that $\mathrm{MH}$ 30 administration in melanoma-bearing mice restored the activity of NK cells as well as the cisplatin-induced reduction of IL-2 and IFN-gamma, with no apparent side effects. These results show that $\mathrm{MH}-30$ has the potential to induce lysis of tumor cells by Tc cells as well as NK cells via IFN-gamma secretion in melanoma-bearing mice, suggesting that $\mathrm{MH}-30$ has anti-cancer drug activities through mechanisms different from chemotherapeutic drugs such as cisplatin.

Although the use of high concentrations of cisplatin is more effective in inhibiting cancer growth, the clinical use of cisplatin is dose-limited due to its unwanted side effects such as bone marrow toxicity, ototoxicity, nephrotoxicity, and hepatotoxicity (15-17). To overcome side effects and 
A

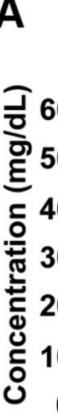

BUN

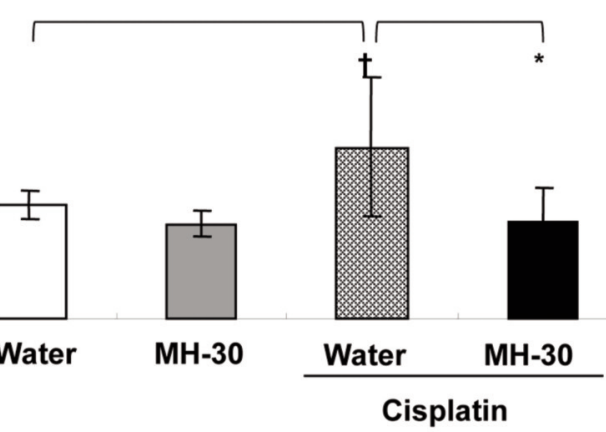

Cisplatin

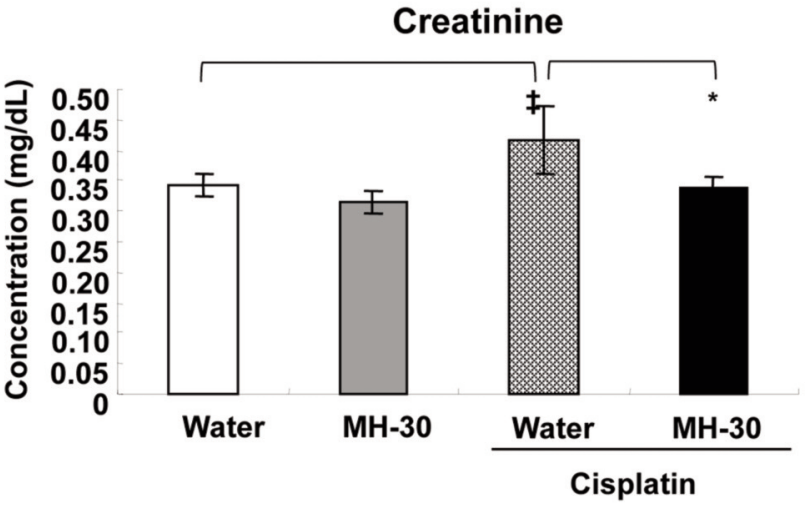

Cisplatin

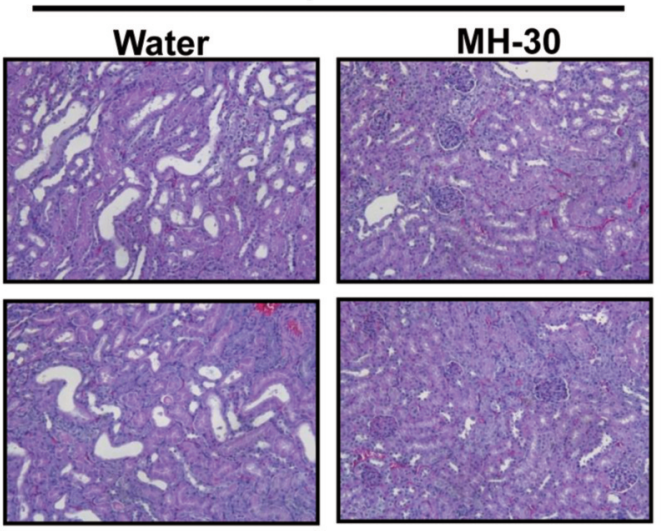

Figure 8. MH-30 administration reduces cisplatin-induce nephrotoxicity. On day 17 after initial injection of cisplatin, serum was prepared through clotting of whole blood collected from the retro-orbital veins and the kidneys were removed and fixed in $10 \%$ buffered formalin for 2 days. (A) The levels of serum BUN and creatinine were analyzed using the AU680 Chemistry System. (B) The paraffin-embedded sections (5 mm thick) were stained with hematoxylin and eosin (H\&E) for histopathological examination and observed under light microscope at '200 magnifications. The result shown is representative cortex from each group. There were twelve mice in each group. Data are presented as the Mean \pm SD. ${ }^{\dagger} p<0.05$ and ${ }^{*} p<0.01$ compared with the control group; * $<0.01$ compared with the only cisplatin treated group.

drug resistance, combination chemotherapy of cisplatin with other chemotherapeutic drugs having different mechanisms of actions is widely reported $(10,18,63)$. Moreover, the most possible mechanism of cisplatin-induced side effects is the increased secretion of ROS such as superoxide anions, hydrogen peroxide and hydroxyl radicals after accumulation in the liver and kidneys, resulting in tissue damage $(15,19)$. For these reasons, many studies have examined whether administration of antioxidants, modulators of nitric oxide, and cytoprotectors, such as amifostine, before cisplatin treatment ameliorates cisplatin-induced toxic side effects (64-66). Whereas there are reports that agents causing oxidative stress such as allopurinol or augmenting lipid peroxidation such as gemcitabine enhance the nephrotoxicity of cisplatin $(67,68)$. In a previous study, MH-30 showed high superoxide and hydroxyl radical scavenging activity (49). Interestingly, antioxidants and scavengers of superoxide anion or hydrogen peroxide prevented necrosis induced by cisplatin in vitro, whereas hydroxyl radical scavengers partially blocked apoptosis caused by lower doses of cisplatin (69). In addition, it has been recently reported that decursin increased the activity of antioxidant enzymes such as glutathione peroxidase, $\mathrm{Cu} / \mathrm{Zn}$ superoxide dismutase (SOD), and catalase, which blocked cisplatin-induced cytotoxicity and apoptosis (70). In the current study, MH-30 administration prevented cisplatin-induced decrease of the liver, kidney and body weight. In addition, the serum levels of AST and ALT indicating hepatotoxicity and BUN and Creatinine indicating nephrotoxicity were effectively decreased by $\mathrm{MH}-30$ administration in cisplatin-injected mice. These results show that $\mathrm{MH}-30$ reduced cisplatininduced adverse effects via antioxidant activity, suggesting that the fat-soluble polyphenols, particularly decursin, in MH-30 contribute to its activity. 
The present study clearly demonstrated that MH-30 in combination with cisplatin efficiently inhibits the melanoma growth, with no apparent undesirable adverse effects. These findings collectively suggest that MH-30 may be used as a safe and effective treatment for malignant tumor cells or as a supplement during conventional chemotherapy.

\section{Conflicts of Interest}

The Authors declare that they have no competing interests regarding this study.

\section{Authors' Contributions}

HRP produced MH-30, carried out all in vitro and in vivo experiments, and wrote the manuscript. HHC performed the cell culture and histopathological examination. UHJ participated in the design of study. SKJ conceived of the study and participated in its design. All Authors have read and approved the manuscript.

\section{Acknowledgements}

This work was conducted under a grant (HI12c-1893) from Ministry of Health and Welfare of Korea. The funders had no role in designing and executing the experiments.

\section{References}

1 Trotter SC, Sora N, Winkelmann RR. Olencki T and Bechtel M: A global review of melanoma follow-up guidelines. J Clin Aesthet Dermatol 6: 18-26, 2013. PMID: 24062870.

$2 \mathrm{Li} \mathrm{Y}$ and McClay EF: Systemic chemotherapy for the treatment of metastatic melanoma. Semin Oncol 29: 413-426, 2002. PMID: 12407507. DOI: 10.1053/sonc.2002.35237

3 Bajetta E, Del Vecchio M, Bernard-Marty C, Vitali M, Buzzoni R, Rixe O, Nova P, Taillibert S and Khayat D: Metastatic melanoma: chemotherapy. Semin Oncol 29: 427-445, 2002. PMID: 12407508. DOI: 10.1053/sonc.2002.35238

4 Song W, Tang Z, Zhang D, Zhang Y, Yu H, Li M, Lv S, Sun H, Deng $M$ and Chen $X$ : Anti-tumor efficacy of c(RGDfK)decorated polypeptide-based micelles co-loaded with docetaxel and cisplatin. Biomaterials 35: 3005-3014, 2014. PMID: 23488813. DOI: 10.1016/j.biomaterials.2013.12.018

$5 \mathrm{Kim} \mathrm{H}$ and Sin JI: Electroporation driven delivery of both an IL12 expressing plasmid and cisplatin synergizes to inhibit B 16 melanoma tumor growth through an NK cell mediated tumor killing mechanism. Hum Vaccin Immunother 8: 1714-1721, 2012. PMID: 23151450. DOI: $10.4161 /$ hv.22356

6 Shin HJ, Kim YS, Kwak YS, Song YB, Kim YS and Park JD: Enhancement of antitumor effects of paclitaxel (taxol) in combination with red ginseng acidic polysaccharide (RGAP). Planta Med 70: 1033-1038, 2004. PMID: 15549658. DOI: $10.1055 / \mathrm{s}-2004-832643$

7 Kalechman Y, Shani A, Dovrat S, Whisnant JK, Mettinger K, Albeck $M$ and Sredni B: The antitumoral effect of the immunomodulator AS101 and paclitaxel (toxol) in a murine model of lung adenocarcinoma. J Immunol 156: 1101-1109, 1996. PMID: 8557985.
8 Kalechman Y, Longo DL, Catane R, Shani A, Albeck M and Sredni B: Synergistic anti-tumoral effect of paclitaxel (Taxol)+AS101 in a murine model of B16 melanoma: association with ras-dependent signal-transduction pathways. Int J Cancer 86: 281-288, 2000. PMID: 10738258. DOI: 10.1002/ (sici) 1097-0215(20000415)86:2<281::aid-ijc20>3.0.co;2-x

9 Huq F, Yu JQ, Beale P, Chan C, Arzuman L, Nessa MU and Mazumder ME: Combinations of platinums and selected phytochemicals as a means of overcoming resistance in ovarian cancer. Anticancer Res 34: 541-545, 2014. PMID: 24403514.

10 Yunos NM, Beale P, Yu JQ and Huq F: Synergism from sequenced combinations of curcumin and epigallocatechin-3gallate with cisplatin in the killing of human ovarian cancer cells. Anticancer Res 31: 1131-1140, 2011. PMID: 21508356.

11 Kadhim S, Penney C, Lagraoui M, Heibein J, Attardo G, Zacharie B, Connolly T and Gagnon L: Synergistic anti-tumor activity of a novel immunomodulator, $\mathrm{BCH}-1393$, in combination with cyclophosphamide. Int J Immunopharmacol 22: 659-671, 2000. PMID: 10884587. DOI: 10.1016/s01920561(00)00028-X

12 Li CJ, Chu CY, Huang LH, Wang MH, Sheu LF, Yeh JI and Hsu HY: Synergistic anticancer activity of triptolide combined with cisplatin enhances apoptosis in gastric cancer in vitro and in vivo. Cancer Lett 319: 203-213, 2012. PMID: 22306340. DOI: 10.1016/j.canlet.2012.01.006

13 Stewart DJ, Benjamin RS, Luna M, Feun L, Caprioli R, Seifert $\mathrm{W}$ and Loo TL: Human tissue distribution of platinum after cisdiamminedichloroplatinum. Cancer Chemother Pharmacol 10: 51-54, 1982. PMID: 6891626. DOI: 10.1007/bf00257239

14 Winston JA and Safirstein R: Reduced renal blood flow in early cisplatin-induced acute renal failure in the rat. Am J Physiol 249: F490-496, 1985. PMID: 4051003. DOI: 10.1152/ajprenal. 1985.249.4.F490

15 Jordan $\mathrm{P}$ and Carmo-Fonseca M: Molecular mechanisms involved in cisplatin cytotoxicity. Cell Mol Life Sci 57: 12291235, 2000. PMID: 11028915. DOI: $10.1007 /$ pl00000762

16 Taguchi T, Nazneen A, Abid MR and Razzaque MS: Cisplatinassociated nephrotoxicity and pathological events. Contrib Nephrol 148: 107-121, 2005. PMID: 15912030. DOI: 10.1159/ 000086055

17 Bodenner DL, Dedon PC, Keng PC, Katz JD and Borch RF: Selective protection against cis-diamminedichloroplatinum(II)induced toxicity in kidney, gut, and bone marrow by diethyldithiocarbamate. Cancer Res 46: 2751-2755, 1986. PMID: 3009000.

18 Ali BH and Al Moundhri MS: Agents ameliorating or augmenting the nephrotoxicity of cisplatin and other platinum compounds: A review of some recent research. Food Chem Toxicol 44: 1173-1183, 2006. PMID: 16530908. DOI: 10.1016/ j.fct.2006.01.013

19 Yao X, Panichpisal K, Kurtzman N and Nugent K: Cisplatin nephrotoxicity: a review. Am J Med Sci 334: 115-124, 2007. PMID: 17700201. DOI: 10.1097/MAJ.0b013e31812dfe1e

20 Boulikas $\mathrm{T}$ and Vougiouka M: Cisplatin and platinum drugs at the molecular level. Oncol Rep 10(6): 1663-1682, 2003. PMID: 14534679.

21 Atessahin A, Yilmaz S, Karahan I, Ceribasi AO and Karaoglu A: Effects of lycopene against cisplatin-induced nephrotoxicity and oxidative stress in rats. Toxicology 212: 116-123, 2005. PMID: 15946783. DOI: 10.1016/j.tox.2005.04.016 
22 Gandara DR, Wiebe VJ, Perez EA, Makuch RW and DeGregorio MW: Cisplatin rescuer therapy: experience with sodium thiosulfate, WR2721, and diethyldithiocarbamate. Crit Rev Oncol Hematol 10: 353-365, 1990. PMID: 2177606. DOI: 10.1016/1040-8428(90)90010-p

23 Kim YK, Jung JS, Lee SH and Kim YW: Effects of antioxidants and $\mathrm{Ca}^{2+}$ in cisplatin-induced cell injury in rabbit renal cortical slices. Toxicol Appl Pharmacol 146: 261-269, 1997. PMID: 9344894. DOI: 10.1006/taap.1997.8252

24 Husain K, Morris C, Whitworth C, Trammell GL, Rybak LP and Somani SM: Protection by ebselen against cisplatin-induced nephrotoxicity: antioxidant system. Mol Cell Biochem 178: 127133, 1998. PMID: 9546591. DOI: 10.1023/a:1006889427520

25 Somani SM, Husain K, Whitworth C, Trammell GL, Malafa M and Rybak LP: Dose-dependent protection by lipoic acid against cisplatin-induced nephrotoxicity in rats: antioxidant defense system. Pharmacol Toxicol 86: 234-241, 2000. PMID: 10862506. DOI: 10.1034/j.1600-0773.2000.d01-41.x

26 Ajith TA, Jose N and Janardhanan KK: Amelioration of cisplatin induced nephrotoxicity in mice by ethyl acetate extract of a polypore fungus, Phellinus rimosus. J Exp Clin Cancer Res 21: 213-217, 2002. PMID: 12148580.

27 Mora Lde O, Antunes LM, Francescato HD and Bianchi Mde L: The effects of oral glutamine on cisplatin-induced nephrotoxicity in rats. Pharmacol Res 47: 517-522, 2003. PMID: 12742005. DOI: 10.1016/s1043-6618(03)00040-9

28 Chirino YI, Hernández-Pando $\mathrm{R}$ and Pedraza-Chaverrí J: Peroxynitrite decomposition catalyst ameliorates renal damage and protein nitration in cisplatin-induced nephrotoxicity in rats. BMC Pharmacol 4: 20, 2004. PMID: 15458572. DOI: 10.1186/ 1471-2210-4-20

29 Lee CK, Park KK, Lim SS, Park JH and Chung WY: Effects of the licorice extract against tumor growth and cisplatin-induced toxicity in a mouse xenograft model of colon cancer. Biol Pharm Bull 30: 2191-2195, 2007. PMID: 17978499. DOI: 10.1248/ bpb.30.2191

30 Engel LW and Straus SE: Development of therapeutics: opportunities within complementary, alternative medicine. Nat Rev Drug Discov 1: 229-237, 2002. PMID: 12120507. DOI: $10.1038 / \mathrm{nrd} 750$

31 Corson TW and Crews CM: Molecular understanding and modern application of traditional medicines: Triumphs and Trials. Cell 130: 769-774, 2007. PMID: 17803898. DOI: 10.1016/j.cell.2007.08.021

32 Youns M, Hoheisel JD and Efferth T: Traditional Chinese medicines (TCMs) for molecular targeted therapies of tumours. Curr Drug Discov Technol 7: 37-45, 2010. PMID: 20156142. DOI: $10.2174 / 157016310791162730$

33 Yuan H, Ma Q, Ye L and Piao G: The traditional medicine and modern medicine from natural products. Molecules 21: E559, 2016. PMID: 27136524. DOI: 10.3390/molecules21050559

34 Park HR, Kim SH, Yee ST, Byun MW and Jo SK: Effect of a herb mixture (HIM-I) on the protection of the hematopoieticimmune system and self-renewal tissues against radiation damage. J Korean Soc Food Sci Nutr 34: 605-612, 2005.

35 Jo SK, Park HR, Jung UH, Oh H, Kim SH and Yee ST: Protective effect of a herbal preparation (HemoHIM) on the selfrenewal tissues and immune system against g-irradiation. J Korean Soc Food Sci Nutr 34: 805-813, 2005. DOI: 10.3746/ jkfn.2005.34.6.805
36 Park HR, Jo SK, Jung U, Kim SH and Yee ST: Immunomodulatory effect of a new herbal preparation (HemoHIM) in cyclophosphamide-treated mice. J Food Sci Nutr 11: 54-60, 2006. DOI: 10.3746/jfn.2006.11.1.054

37 Kim SH, Lee HJ, Kim JS, Moon C, Kim JC, Park HR, Jung U, Jang JS and Jo SK: Protective effect of an herbal preparation (HemoHIM) on radiation-induced intestinal injury in mice. J Med Food 12: 1353-1358, 2009. PMID: 20041793. DOI: $10.1089 /$ jmf. 2008.1322

38 Park HR, Jo SK, Choi NH and Jung U: HemoHIM ameliorates the persistent down-regulation of Th1-like immune responses in fractionated $\gamma$-irradiated mice by modulating the IL-12p70STAT4 signaling pathway. Radiat Res 177: 676-684, 2012. PMID: 22439601. DOI: 10.1667/rr2768.1

39 Kim JJ, Choi J, Lee MK, Kang KY, Pail MJ, Jo SK, Jung U, Park HR and Yee ST: Immunomodulatory and antidiabetic effects of a new herbal preparation (HemoHIM) on streptozotocin-induced diabetic mice. Evid Based Complement Alternat Med 2014: 461685, 2014. PMID: 25045390. DOI: $10.1155 / 2014 / 461685$

40 Jo SK, Lee JJ, Kim SR, Kim JC, Bae CS, Jung U, Park HR, Jang JS and Kim SH: Antiinflammatory activity of an herbal preparation (HemoHIM) in rats. Phytother Res 21: 625-628, 2007. PMID: 17486680 . DOI: $10.1002 /$ ptr.2068

41 Park HR, Jo SK, Jung U and Yee ST: Restoration of the immune functions in aged mice by supplementation with a new herbal composition, HemoHIM. Phytother Res 22: 36-42, 2008. PMID: 17705143. DOI: $10.1002 /$ ptr.2255

42 Kim JJ, Jo SK, Jung U, Park HR and Yee ST: Inhibitory effects of a herbal composition (HemoHIM) on the activation of human mast cell line (HMC-1). J Life Sci 19: 1808-1814, 2009. DOI: 10.5352/JLS.2009.19.12.1808

43 Kim JJ, Cho HW, Park HR, Jung U, Jo SK and Yee ST: Preventative effect of an herbal preparation (HemoHIM) on development of airway inflammation in mice via modulation of Th1/2 cells differentiation. PLOS One 8: e68552, 2013. PMID: 23844220. DOI: 10.1371/journal.pone.0068552

44 Lee SJ, Kim JJ, Kang KY, Hwang YH, Jeong GY, Jo SK, Jung U, Park HR and Yee ST: Herbal preparation (HemoHIM) enhanced functional maturation of bone marrow-derived dendritic cells mediated toll-like receptor 4. BMC Complement Altern Med 16: 67, 2016. PMID: 26891999. DOI: 10.1186/ s12906-016-1045-9

45 Park HR, Ju EJ, Jo SK, Jung U, Kim SH and Yee ST: Enhanced antitumor efficacy of cisplatin in combination with HemoHIM in tumor-bearing mice. BMC Cancer 9: 85, 2009. PMID: 19292900. DOI: 10.1186/1471-2407-9-85

46 Park HR, Ju EJ, Jo SK, Jung U and Kim SH: HemoHIM enhances the therapeutic efficacy of ionizing radiation treatment in tumor-bearing mice. J Med Food 13: 47-53, 2010. PMID: 20136435. DOI: $10.1089 /$ jmf.2009.1049

47 Chaudhary S, Chandrashekar KS, Pai KS, Setty MM, Devkar RA, Reddy ND and Shoja MH: Evaluation of antioxidant and anticancer activity of extract and fractions of Nardostachys jatamansi DC in breast carcinoma. BMC Complement Altern Med 15: 50, 2015. PMID: 25886964. DOI: 10.1186/s12906-015-0563-1

48 Asghar N, Naqvi SA, Hussain Z, Rasool N, Khan ZA, Shahzad SA, Sherazi TA, Janjua MR, Nagra SA, Zia-Ul-Haq M and Jaafar HZ: Compositional difference in antioxidant and antibacterial activity of all parts of the Carica papaya using 
different solvents. Chem Cent J 10: 5, 2016. PMID: 26848308. DOI: 10.1186/s13065-016-0149-0

49 Jung U, Park HR, Lee HY, Baek GY and Jo SK: Protective effects of new herbal composition (MH-30) against radiation injuries in hematopoietic and self-renewal tissues. J Korean Soc Food Sci Nutr 45: 948-957, 2016. DOI: 10.3746/jkfn.2016.45.7.948

50 Mondal S, Bandyopadhyay S, Ghosh MK, Mukhopadhyay S, Roy S and Mandal C: Natural products: promising resources for cancer drug discovery. Anticancer Agents Med Chem 12: 49-75, 2012. PMID: 21707502. DOI: $10.2174 / 187152012798764697$

51 Song JY, Han SK, Son EH, Pyo SN, Yun YS and Yi SY: Induction of secretory and tumoricidal activities in peritoneal macrophages by ginsan. Int Immunopharmacol 2: 857-865, 2002. PMID: 12188027. DOI: 10.1016/s1567-5769(01)00211-9

52 Woo SM, Choi YK, Cho SG, Park S and Ko SG: A new herbal formula, KSG-002, suppresses breast cancer growth and metastasis by targeting NF-KB dependent TNF $\alpha$ production in macrophages. Evid Based Complement Alternat Med 2013: 728258, 2013. PMID: 23818931. DOI: $10.1155 / 2013 / 728258$

53 Yim D, Singh RP, Agarwal C, Lee S, Chi H and Agarwal R: A novel anticancer agent, decursin, induces G1 arrest and apoptosis in human prostate carcinoma cells. Cancer Res 65: 1035-1044, 2005. PMID: 15705905.

54 Song GY, Lee JH, Cho M, Park BS, Kim DE and Oh S: Decursin suppresses human androgen-independent PC3 prostate cancer cell proliferation by promoting the degradation of $\beta$ catenin. Mol Pharmacol 72: 1599-1606, 2007. PMID: 17855653. DOI: $10.1124 / \mathrm{mol} .107 .040253$

55 Kim WJ, Lee SJ, Choi YD and Moon SK: Decursin inhibits growth of human bladder and colon cancer cells via apoptosis G1-phase cell cycle arrest and extracellular signal-regulated kinase activation. Int J Mol Med 25: 635-641, 2010. PMID: 20198313. DOI: 10.3892/ijmm_00000386

56 Kim BS, Seo H, Kim HJ, Bae SM, Son HN, Lee YJ, Ryu S, Park RW and Nam JO: Decursin from Angelica gigas Nakai inhibits B16F10 melanoma growth through induction of apoptosis. J Med Food 18: 1121-1127, 2015. PMID: 26336081. DOI: 10.1089/jmf.2014.3397

57 Herberman RB: Cancer immunotherapy with natural killer cells. Semin Oncol 29: 27-30, 2002. PMID: 12068385. DOI: 10.1053/sonc. 2002.33079

58 Trinchieri G: Biology of natural killer cells. Adv Immunol 47: 187376, 1989. PMID: 2683611. DOI: 10.1016/s0065-2776(08)60664-1

59 Vivier E, Tomasello E, Baratin M, Walzer T and Ugolini S: Functions of natural killer cells. Nat Immunol 9: 503-510, 2008. PMID: 18425107. DOI: 10.1038/ni1582

60 Barth Jr RJ, Mule JJ, Spiess PJ and Rosenberg SA: Interferon g and tumor necrosis factor have a role in tumor regressions mediated by murine CD8 tumor-infiltrating lymphocytes. J Exp Med 173: 647-658, 1991. PMID: 1900079. DOI: 10.1084/ jem.173.3.647

61 Shankaran V, Ikeda H, Bruce AT, White JM, Swanson PE, Old LJ and Schreiber RD: IFN gamma and lymphocytes prevent primary tumour development and shape tumour immunogenicity. Nature 410: 1107-1111, 2001. PMID: 11323675. DOI: 10.1038/ 35074122
62 Ridolfi R, Flamini E, Riccobon A, De Paola F, Maltoni R, Gardini A, Ridolfi L, Medri L, Poletti G and Amadori D: Adjuvant adoptive immunotherapy with tumour-infiltrating lymphocytes and modulated doses of interleukin-2 in 22 patients with melanoma, colorectal and renal cancer, after radical metastasectomy, and in 12 advanced patients. Cancer Immunol Immunother 46: 185-193, 1998. PMID: 9671141 . DOI: 10.1007/s002620050477

63 Ozben T: Mechanisms and strategies to overcome multiple drug resistance in cancer. FEBS Lett 580: 2903-2909, 2006. PMID: 16497299. DOI: 10.1016/j.febslet.2006.02.020

64 Francescato HD, Coimbra TM, Costa RS and Bianchi Mde L: Protective effect of quercetin on the evolution of cisplatininduced acute tubular necrosis. Kidney Blood Press Res 27: 148158, 2004. PMID: 15118361. DOI: 10.1159/000078309

65 Ozen S, Akyol O, Iraz M, Sogut S, Ozugurlu F, Ozyurt H, Odaci $\mathrm{E}$ and Yildirim Z: Role of caffeic acid phenethyl ester, an active component of propolis, against cisplatin-induced nephrotoxicity in rats. J Appl Toxicol 24: 27-35, 2004. PMID: 14745844. DOI: $10.1002 /$ jat.941

66 Naziroglu M, Karaoglu A and Kksoy AO: Selenium and high dose vitamin $\mathrm{E}$ administration protects cisplatin-induced oxidative damage to renal, liver and lens tissues in rats. Toxicology 195: 221-230, 2004. PMID: 14751677. DOI: 10.1016/j.tox.2003.10.012

67 Erdinc M, Erdinc L, Nergiz Y and Isik B: Potentiation of cisplatin-induced nephrotoxicity in rats by allopurinol. Exp Toxicol Pathol 52: 329-334, 2000. PMID: 10987186. DOI: 10.1016/s0940-2993(00)80058-5

68 Saad SY, Najjar TA, Noreddin AM and Al-Rikabi AC: Effects of gemcitabine on cisplatin-induced nephrotoxicity in rats: schedule-dependent study. Pharmacol Res 43: 193-198, 2001. PMID: 11243722. DOI: 10.1006/phrs.2000.0764

69 Baek SM, Kwon CH, Kim JH, Woo JS, Jung JS and Kim YK: Differential roles of hydrogen peroxide and hydroxyl radical in cisplatin-induced cell death in renal proximal tubular epithelial cells. J Lab Clin Med 142: 178-186, 2003. PMID: 14532906. DOI: $10.1016 / \mathrm{S} 0022-2143(03) 00111-2$

70 Kim JH, Jeong SJ, Kwon HY, Park SY, Lee HJ, Lee HJ, Lieske JC and Kim SH: Decrusin prevents cisplatin-induced apoptosis via the enhancement of antioxidant enzymes in human renal epithelial cells. Biol Pharm Bull 33: 1279-1284, 2010. PMID: 20686219. DOI: $10.1248 / \mathrm{bpb} .33 .1279$
Received March 26, 2020

Revised April 10, 2020

Accepted April 12, 2020 